\title{
Relationship between channelisation and geometric characteristics of road pavements
}

\section{Renan Sinanmis and Lee Woods}

Traffic loading is the primary factor considered when designing a pavement. It is suggested in some design guides that the spread of the traffic load across the pavement surface should be considered alongside the standard axle loading the pavement will need to carry over its lifespan. However, there is little guidance on how to predict the spread of traffic loads when designing a new pavement, and empirical studies supporting any such guidance is also limited. This study helps to address this gap through analyses of data collected on the vehicle positions on 100 sections of pavement in Portsmouth, United Kingdom. The analyses, found a positive linear association between the degree of lateral wander and both the lane width and road width. These results suggest that the use of a binary measure of vehicle position used in the UK design guidance may not be suitable. The results also highlight the importance of both lane and road width, contrary to the existing body of research that indicates only one or the other to be a determinant of vehicle position. These findings have significant potential benefits to pavement engineers when estimating the lifespan of new pavements.

Keywords:

Traffic loading, lateral wander, channelisation, pavement design. 


\section{Introduction}

Highway pavements provide the transport network for most travel undertaken in the world, and provide the space for various other activities to take place. Key to ensuring the performance of a pavement is predicting the stresses, strains and weather conditions that the pavement will need to endure over its lifespan. A large body of literature has found many factors that influence the deterioration, and hence lifespan, of pavements. The key determinant has been found to be the amount and type of traffic exerting a load on the pavement surface (Buiter et al. 1989, Blab and Litzka 1995, Atkinson et al. 2006). Hence, various design standards and guides convert different vehicle types into standard axle loads and wear factors. In the United Kingdom (UK), the wear factors specified in the design standard (Highways Agency 2006) are derived from the fourth power law, where the damaging effect is proportional to the fourth power of the load exerted by a vehicle's wheel onto the surface. It should be noted that other studies have suggested a value larger than 7 could be applicable depending on the pavement type and expected traffic (Dormon and Metcalf 1965, Jameson 1996, Dawson 2008). Studies and design codes around the world highlight that load repetitions by heavy vehicles especially, results in considerable deterioration (Collop 2002, Erlingsson et al. 2012). Whilst there is a large body of evidence as to the damaging effect of different vehicle types on pavements, there is less evidence and guidance as to whether the distribution of traffic loads over the cross section of the pavement influences this, and less still on how the cross sectional spread of loading should be predicted. The spread in position of vehicles across a pavement surface is referred to as 'lateral wander'. In instances where there is very little lateral wander, the traffic can be referred to as 'channelised'. In channelised traffic, successive vehicles follow the same wheel path over a narrower section of the pavement surface. Channelised traffic might be expected at narrow sections of pavement such as 
traffic calming gateways, bus stops or car parks (Walsh 2011). Channelised traffic is usually considered to have a more detrimental impact on the pavement than traffic with a high degree of lateral wander (Walsh 2011). Some design guides account for the effects of channelisation by increasing the traffic loading predicted to be carried by the pavement over its lifespan (Garrett 1983, ARA 2004, Walsh 2011). Pavements can then be designed with stronger materials or thicker layers to avoid premature deterioration. Such deterioration could include surface cracking, loss of texture, and in the case of flexible asphalt pavements, severe rutting, as can be seen in Figure 1.

[Insert Figure 1]

\section{Geometric characteristics and lateral wander of traffic loading}

To date, several studies have investigated the lateral distribution of traffic on pavements. Some have found associations between lateral wander and road width (Pauls 1925, Taragin 1945), and others with lane width (Case et al. 1953, Miller and Steuart 1982, Erlingsson et al. 2012), as pavements with wider sections tend to have a relatively larger spread of traffic while narrow sections can have highly channelised traffic patterns. Other studies found the lateral distribution of vehicle positions related to other characteristics of the road, such as horizontal curves and their visual impression, gradients, shoulder widths, roundabout circles, and kerb heights (Pauls 1925, Taragin 1944, Case et al. 1953, Summala et al. 1978, Weise et al. 1997, Gunay and Woodward 2007, van der Walt et al. 2017), and also based on vehicle type and composition (Taragin 1944, Miller and Steuart 1982). Additionally, edge line markings and their width appeared to be related to the lateral spread of cars causing drivers to travel towards to the centreline of the road (Nedas et al. 1982, Van Driel et al. 2004). A relationship with vehicle speed has also been suggested with speed influencing vehicle 
position and vice versa (Summala et al. 1978, Blab and Litzka 1995, Hallmark et al. 2013).

Finally, rutting has been found to be associated with channelised traffic (Blab and Litzka 1995, Erlingsson et al. 2012). It is unclear as to the causality, but it is suggested that there is a feedback loop with channelisation causing rutting, which then further exacerbates the channelisation and so on (Blab and Litzka 1995, Aydin and Topal 2016).

\section{Channelisation in pavement design guidance}

The first study to consider channelisation as a factor in the calculations of design traffic in the UK was conducted by Kent County Council in 1983 and suggested applying a factor of 2 to the total traffic load to represent a doubling of the damaging effect of the traffic loading that might be expected under channelised (referred to as canalised in the paper) conditions (Garrett 1983). The rationale for the factor of two appears to be based on a theoretical consideration of a normal distribution of vehicle positions on a wide lane and narrow lane as shown in Figure 2. However, what would constitute a wide or narrow lane is not defined. Whilst the UK design standards (Highways Agency 2006), do not consider channelisation effects, several widely used supplementary design guides do. The Institution of Civil Engineers Manual (Walsh et al. 2011) suggests that when channelised traffic is expected, the traffic loading is doubled. The rationale for this advice relates back to the theoretical work undertaken by Kent County Council (Garrett 1983). As with the theoretical work, little is said in the design guides as to when such channelisation might occur. This design guidance and the underpinning theory do not consider degrees of channelisation, but instead suggest only a binary measure (channelised or unchannelised). 
[Insert Figure 2]

In other national design guides, the distribution of traffic loading across the pavement is considered on a scale, based on the width of lane. For instance, according to the German Road Design Manual, channelisation is considered on a scale based on lane widths from 2.50 metres where full channelisation is expected through to 3.75 metres where no channelisation is expected (Sieber 2012).

Similarly Austrian design guidance, informed by the study conducted by Blab and Litzka (1995) considers lane width, measured on a scale, to be the only factor that determines the lateral wander of vehicles.

Likewise, in the Netherlands the lane width is considered to have a linear relationship with the damage caused by the traffic due to the effect on the distribution of the loads (Buiter et al. 1989).

Based on consideration of international design standards and the somewhat limited research underpinning them, it seems plausible that the degree of vehicle wander ought not be a binary judgement as is the case in the UK design guidance. Those geometric characteristic that might affect the degree of wander in the UK and whether these differ from international design guides is currently unknown.

\section{Summary of literature}

Little evidence exists as to how to categorise traffic flow as either channelised or not when designing a pavement in the UK. However, when traffic is considered to be channelised a factor of ' 2 ' is applied, which stems from theoretical considerations of the distribution of wheel positions.

Design guides in other countries, suggest the use of 'lane width' as a proxy for vehicle wander/channelisation. However, the empirical evidence supporting the use of these values is limited. Moreover, as pavement designs, materials, maximum vehicle 
loading, weather conditions, soil conditions, maintenance regimes, road markings, traffic laws and vehicle types differ considerably between different countries, the results of studies in one context cannot be assumed to hold in other contexts.

Furthermore, those studies cited here tend to be based on either theoretical models or laboratory experiments. Field observations are likely to give a better representation of actual driving behaviours and none have been found that are applicable to the UK. Therefore this study aims to address this gap in knowledge and provide guidance to practitioners in the UK and overseas on the factors that might influence vehicle wander.

\section{Data collection and Methodology}

This study investigated the effects of road geometry and features on the degree of channelisation through observations in the City of Portsmouth, UK as shown in Figure 3.

Specifically, the A288 Clarence Parade/South Parade (Figure 3) was selected because the pavement type was consistent along its length (Heavy Duty Macadam with $0 / 20 \mathrm{~mm}$ aggregate and 50 penetration binder), there was minimal variation in traffic flow/composition in climatic and in soil conditions along its length, while the geometry and presence of road features varied considerably. There were a number of side roads and a mini roundabout along the length of the road. However these were excluded as they would have a very odd profile of vehicle positions, due to the combination of turning and through traffic at those points.

[Insert Figure 3] 


\section{Measurements}

The positions of vehicles were measured using a photogrammetric technique to account for the perspective caused by the recording being taken from an oblique angle. An HD GoPro camcorder, with high resolution quality, was placed on the pedestrian footway/sidewalk and the traffic passing between two levelling staffs were recorded (Figure 4).

[Insert Figure 4]

After recorded the traffic footage, a perspective grid was drawn between the two levelling staffs and then superimposed over the video as shown in Figure 5. Each passing vehicle was then measured using this perspective grid and converted in Metres. The error associated with the measurement method was tested, by using the method to measure known distances. These tests suggested that the error associated with the method was only $1 \mathrm{~mm}$ in every $1 \mathrm{~m}$. However, measuring the position of each wheel in the field, it was not possible to achieve such a fine level of precision. The measurements in the field were taken visually and manually to the nearest $50 \mathrm{~mm}$. The distance measured was from the nearside kerb to the inner face of the front nearside wheel. As such, the accuracy of the measurements is thought to be $50 \mathrm{~mm}$.

The standard deviation of the first 105 vehicles passing through the survey location was calculated as the measure of the degree of channelisation. This method was repeated at 100 different locations along the case study road between July and November 2018 (10,500 vehicles recorded in total).

Power analyses determined that this sample size provided an $80 \%$ chance of detecting a statistically significant difference in the standard deviations (degree of channnelisation) between the different locations. It was therefore felt that the sample size selected gave a high chance of detecting any differences found. 
By selecting these 100 locations, at approximately $10 \mathrm{~m}$ intervals, it was possible to gain variation in following:

- Presence of a nearside parked vehicle,

- Presence of a nearside cycle lane,

- Presence of zig-zag road markings,

- Presence of nearside hatching,

- Presence of a central reservation,

- Road and lane widths.

The features were recorded visually as either being present or not (binary) at the immidiate location of the observation. Road widths and lane widths were measured using a laser distance meter device (Leica DISTOTM X310), with roadwith being the kerb to kerb distance and lane width being between the nearside and offside lane markings.

[Insert Figure 5]

\section{Results and Data Analysis}

Tables 1 and 2 show the range of values for the road geometries and presence of road features for the 100 sections.

[Insert Table 1]

[Insert Table 2]

Frequency distributions for the widest, narrowest and average lane width road sections are shown in Figure 6. The lateral distribution of vehicles across the road sections were found to be normally distributed. 


\section{[Insert Figure 6]}

The scatterplots shown in Figure 7 suggest a positive correlation between the degree of channelisation and both lane width and road width based on Pearson Correlation Coefficient, $r_{\text {lane_width }}=0.675$ and $r_{\text {road_width }}=0.650$, p-value $<.001$ (lower degree of channelisation is correlated with wider sections).

\section{[Insert Figure 7]}

Boxplots of channelisation compared to the presence or otherwise of each road feature can be seen in Figure 8.

Independent samples T-tests were undertaken on each feature to estimate whether its presence or otherwise was associated with a difference in the mean of the standard deviation. That is, whether the presence of a road feature is associated with the degree of channelisation. The results suggested that there is no statistically significant effect on degree of channelisation for presence of parked vehicles ( $p$-value $=0.407)$, central reservation $(p$-value $=0.793)$ and nearside hatching $(p$-value $=0.268)$. However, there is a significant difference in presence of zigzag lines $(p$-value $=0.021)$ and cycle lane $(p$-value $=0.013)$.

\section{[Insert Figure 8]}

Multi-variate linear regression analyses were used to model the associations between channelisation and all factors and covariates. The Standard Deviation (SD) of vehicles positions at each of the 98 road sections were used as the dependent variable to represent the degree of channelisation. Two road sections were removed from the original 100 as they were outliers. The two outliers related to sections that were very close to, or on, road junctions, and so were felt to be un-representative of usual highway sections. 
A stepwise removal method was used to determine the best combination of explanatory variables, both in terms of their main effects and also interaction effects. Through this modelling, the road features (presence of parked vehicles, zig zag lines, cycle lanes, central reservation and nearside hatching) were found to be neither significant (at the 95\% level) nor to have a large magnitude of effect. Moreover, they had little impact on the overall explanatory power of the model (adjusted- $\mathrm{R}^{2}$ value). Therefore, the final model contains only two explanatory variables; road width and lane width, as seen in the following model outputs.

[Insert Table 3]

$\mathrm{Y}($ standard deviation $)=-0.006+0.033 \mathrm{X}_{1}($ lane_width $)+0.017 \mathrm{X}_{2}($ road_width $)$

The regression analysis shows that both lane and road width are highly statistically significant ( $p$-values $<.001)$. The magnitudes of effect vary. For Lane Width (m) $1 \mathrm{~m}$ wider, the standard deviation of vehicle position increases by $0.033 \mathrm{~m}$ (95\% confidence interval $=0.018$ to 0.047$)$. To put this into context, the variation in Lane Width in the dataset was from a minimum of $3.40 \mathrm{~m}$ to a maximum of $14.19 \mathrm{~m}$. Using the model output, this would equate to a difference in the degree of channelisation of $0.36 \mathrm{~m}$.

For Road Width, for every $1 \mathrm{~m}$ wider, the standard deviation of the vehicle position increases by $0.017 \mathrm{~m}$ (95\% confidence interval 0.008 to 0.026$)$. Road width in the dataset ranged from a minimum of $5.50 \mathrm{~m}$ to $22.7 \mathrm{~m}$. This range would relate to a difference in the degree of channelisation of $0.29 \mathrm{~m}$.

The overall model fit is adjusted- $\mathrm{R}^{2}=0.517$ which is shown in scatterplot in Figure 9.

[Insert Figure 9] 
Considering the combined effects, the section with the narrowest lane and road width would be expected to have a standard deviation of vehicle positon of $0.23 \mathrm{~m}$, and the widest lane and road width of $0.83 \mathrm{~m}$.

\section{Discussions and Conclusions}

This study investigated the impact of road dimensions and presence of road features on the degree of channelisation.

No road features were found to be related to the degree of channelisation, but both lane width and road width were. Although none of the road features were found to be statistically significantly associated with the degree of channelisation, it may be the case that this was due to the relatively small number of sites that contained particular road features. Also, the road features were described in binary terms: present or not present.

It is highly plausible that if the road features had been considered as scalable measurements of their cross sectional width, then they may have been statistically significant. The reason for such a supposition is that the road width was measured from one kerb to the other, the lane width from the nearside to offside lane markings, and the difference between the two measurements was made up by the widths of any road features. Therefore, the difference between the road and lane width negates the need to consider the presence or otherwise of any road feature. For example, on a section of road with a cycle lane and a central reservation, the road width might be $11 \mathrm{~m}$ and the lane widths $4 \mathrm{~m}$ each. The $3 \mathrm{~m}$ difference between the combined widths of the lanes and the width of the road would relate to the two $1 \mathrm{~m}$ wide cycle lanes at either side of the road and $1 \mathrm{~m}$ wide of central reservation in the middle of the road. As such, the presence of any particular road feature in itself does not appear to be significant but the combined width of all road features present does. The can be seen in the Figure 10 
showing a section of the case study highway with a cycle lane and central reservation. The presence of the road features causes there to be a large difference in the width of the road compared to the width of the lanes.

[Insert Figure 10]

Whilst it may be interesting to rerun the analyses with road features considered as scalable measurements, the results that this might produce are likely to be less helpful to highway engineers. The current results enable a highway engineer to take just two dimensions (road and lane width) to estimate the degree of channelisation. If the individual roadside features were found to be significant as scalable measurements, highway engineers would need to take many more measurements to estimate the standard deviation of wheel positions as opposed to just two measurements. Further work could consider widths of features but the results presented here remain both statistically robust and also practically useful.

It is suggested here that drivers do alter their lateral position as a result of features outside of their traffic lane and do so depending on the width of these features. These combined features relate to the difference between lane and road width. This new finding contributes to the knowledge on the causes of traffic channelisation. These findings partially support international standards that use lane width as a proxy for the degree of channelisation (Netherlands, Austrian, German) rather than the current binary measures used in UK guidance (Walsh 2011). However, it should be borne in mind that the results presented here do not consider the damaging effect of this channelisation on the pavement, whereas the design standard and guides do.

No design guides, nor standards, consider that road width alongside lane width ought to be considered, whereas this study indicates that by doing so, highway engineers would be better able to estimate the degree of channelization, and hence the 
effective traffic loading a pavement would need to carry. These findings could therefore enable more accurate estimations of the design lives of pavements to be made, and/or for pavements to be better designed and maintained to meet specified lifespans.

Although not presented here, subsequent work has been undertaken on how the degree of channelisation recorded on the case study road sections relates to the deterioration of the pavement. Further work could consider case study road sections with very narrow widths to determine whether the results found here can be extrapolated to extreme cases. 


\section{References}

Ara, I., Eres Consultants Division., 2004. Guide for mechanistic-empirical design of new and rehabilitated pavement structures. Final Rep., NCHRP Project 1-37A.

Atkinson, V., Merrill, D. \& Thom, N., 2006. Pavement wear factors, 1st ed. Wokingham, Berkshire: TRL.

Aydin, M.M. \& Topal, A., 2016. Effect of road surface deformations on lateral lane utilization and longitudinal driving behaviours. Transport, 31 (2), 192-201.

Blab, R. \& Litzka, J., Year. Measurements of the lateral distribution of heavy vehicles and its effects on the design of road pavementsed.^eds. Proceedings of the International Symposium on Heavy Vehicle Weights and Dimensions, Road Transport Technology, University of Michigan, 389-395.

Buiter, R., Cortenraad, W., Van Eck, A. \& Van Rij, H., 1989. Effects of transverse distribution of heavy vehicles on thickness design of full-depth asphalt pavements. Transportation Research Record, (1227).

Case, H.W., Hulbert, S.F., Mount, G.E. \& Brenner, R., Year. Effect of a roadside structure on lateral placement of motor vehiclesed.^eds. Highway Research Board Proceedings.

Collop, A., Year. Traffic characterisation in flexible pavement designed.^eds. International Symposium on Heavy Vehicle Weights and Dimensions, 7th, 2002, Delft, The Netherlands.

Dawson, A.R., 2008. Rut accumulation and power law models for low-volume pavements under mixed traffic. Transportation Research Record, 2068 (1), 7886.

Dormon, G. \& Metcalf, C., 1965. Design curves for flexible pavements based on layered system theory. Highway Research Record, 71, 69-84.

Erlingsson, S., Said, S. \& Mcgarvey, T., Year. Influence of heavy traffic lateral wander on pavement deterioration. In: (Vti), S.N.R.a.T.R.I., ed.^eds. 4th European Pavement and Asset Management Conference, Malmo, Sweden.

Garrett, C., 1983. Vehicle damage factors present, past and future values. Kent County Council The County Surveyors' Society. 
Gunay, B. \& Woodward, D., Year. Lateral position of traffic negotiating horizontal bendsed.^eds. Proceedings of the Institution of Civil EngineersTransport Thomas Telford Ltd, 1-11.

Hallmark, S.L., Hawkins, N. \& Smadi, O., Year. Relationship between speed and lateral position on curvesed. ${ }^{\wedge}$ eds. 16th International Conference Road Safety on Four Continents. Beijing, China (RS4C 2013). 15-17 May 2013Statens väg-och transportforskningsinstitut.

Highways Agency, 2006. Design manual for roads and bridges volume 7 section 2 part 3 hd 26/06: Pavement design In Agency, H. ed. England: TSO (The Stationery Office).

Jameson, G., 1996. Origins of austroads design procedures for granular pavements.

Miller, E.J. \& Steuart, G.N., 1982. Vehicle lateral placements on urban roads. Transportation engineering journal of the American Society of Civil Engineers, 108 (TE5), 495-508.

Nedas, N.D., Balcar, G.P. \& Macy, P.R., 1982. Road markings as an alcohol countermeasure for highway safety: Field study of standard and wide edgelines. Abridgment, 0309033500.

Pauls, J., 1925. Transverse distributions of motor vehicle traffic on paved highways. Public Roads, 6 (1), 1-13.

Sieber, R., 2012. Richtlinien für die standardisierung des oberbaus von verkehrsflächen: Rsto 12: FGSV Verlag.

Summala, H., Merisalo, A. \& Vierimaa, J., 1978. Tutkimus ajoneuvojen sijainnista tien poikkileikkauksessa. Finnish, 9514634799.

Taragin, A., Year. Transverse placement of vehicles as related to cross section designed.^eds. Highway Research Board Proceedings.

Taragin, A., Year. Effect of roadway width on traffic operations-two-lane concrete roadsed.^eds. Highway Research Board Proceedings.

Van Der Walt, J., Scheepbouwer, E. \& West, N., 2017. Positioning of travelling vehicles in rural new zealand on chip sealed roads. Journal of Structural Integrity and Maintenance, 2 (4), 227-233.

Van Driel, C.J., Davidse, R.J. \& Van Maarseveen, M.F., 2004. The effects of an edgeline on speed and lateral position: A meta-analysis. Accident Analysis \& Prevention, 36 (4), 671-682.

Walsh, I.D., 2011. Chapter 36 pavement design (highways). Ice manual of highway design and management. 325-351.

Walsh, I.D., A Hunter, R.N., A Darrall, L., A Matthews, P., A Jameson, P. \& A Thorp, J., 2011. Ice manual of highway design and management. 
Weise, G., Steyer, R., Sossoimihen, A. \& Roeder, D., Year. Lateral placement of vehicles on curves of two-lane rural roads as safety criterioned. ${ }^{\wedge}$ eds. XIIIth World meeting of the International Road FederationInternational Road Federation. 

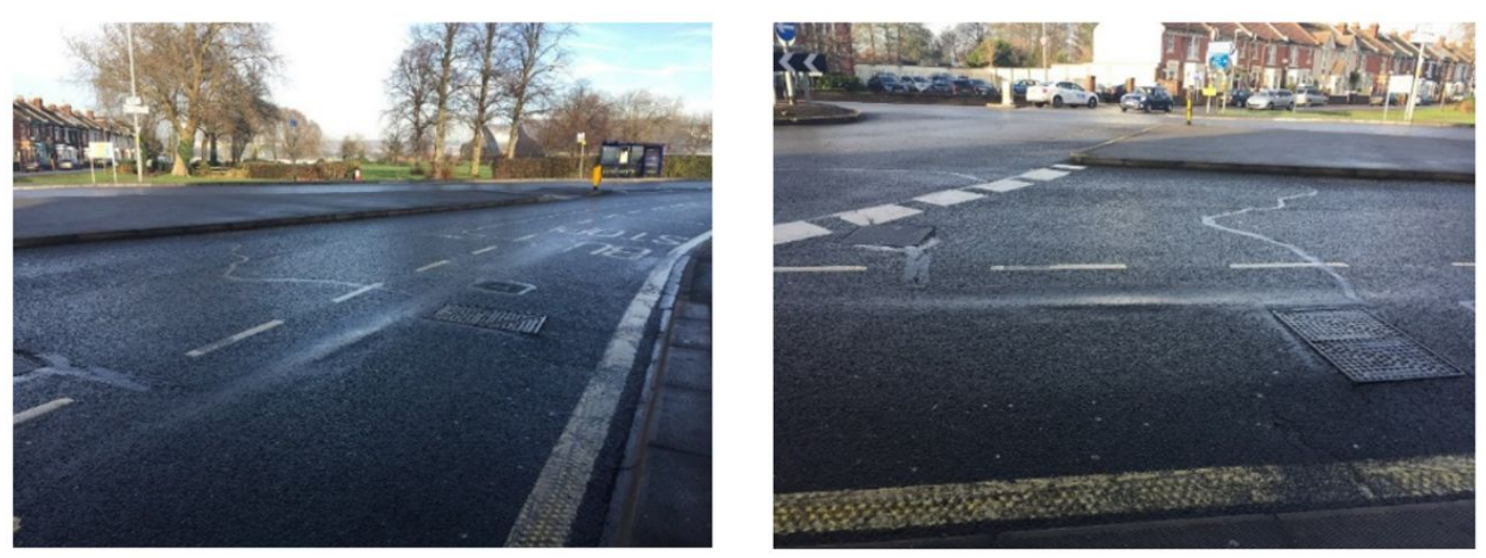

Figure 1. Rutting and polishing caused by channelisation on pavements in Portsmouth

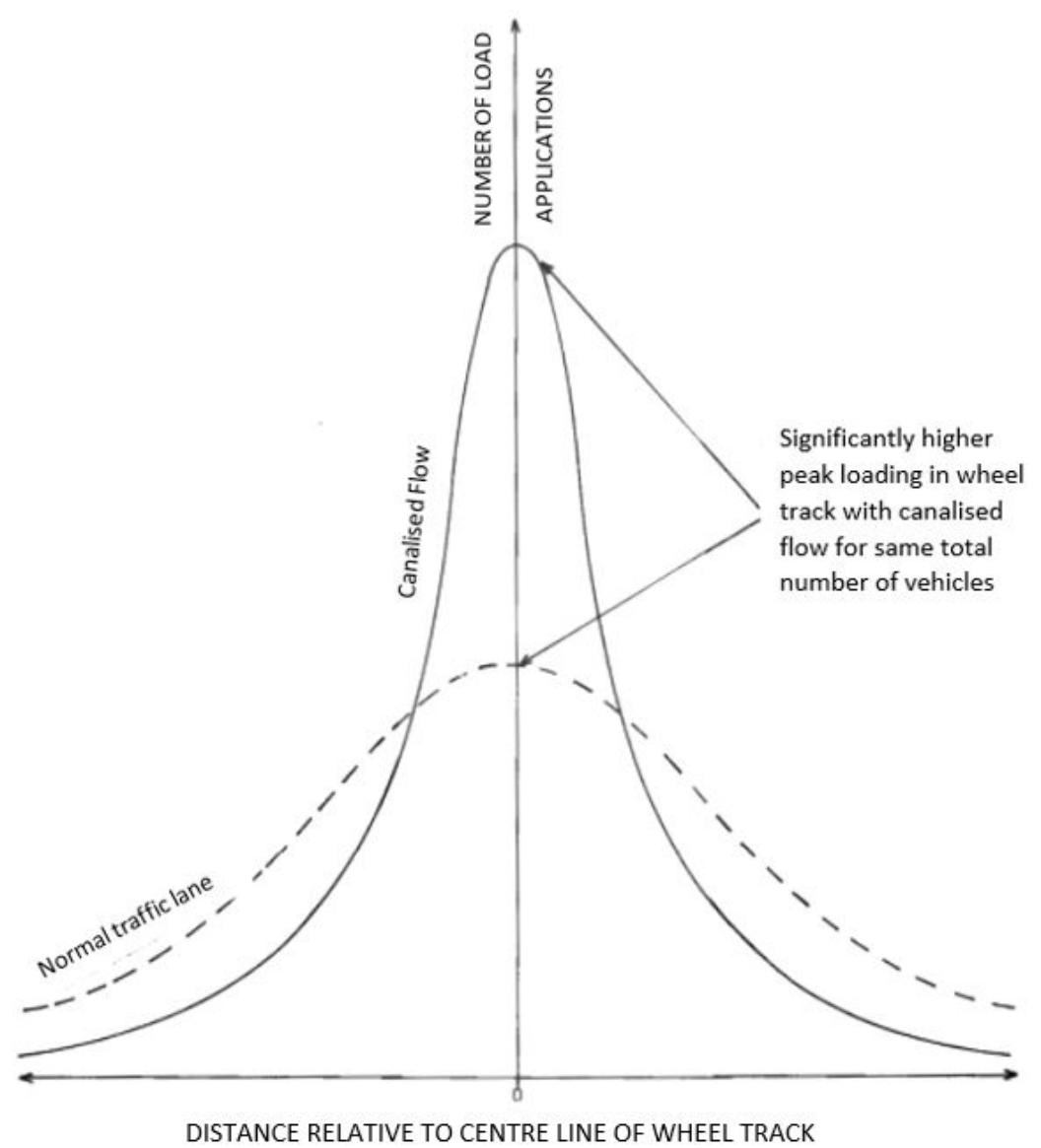

Figure 2. Effect of canalised traffic flow on peak damaging power (Garrett 1983) 


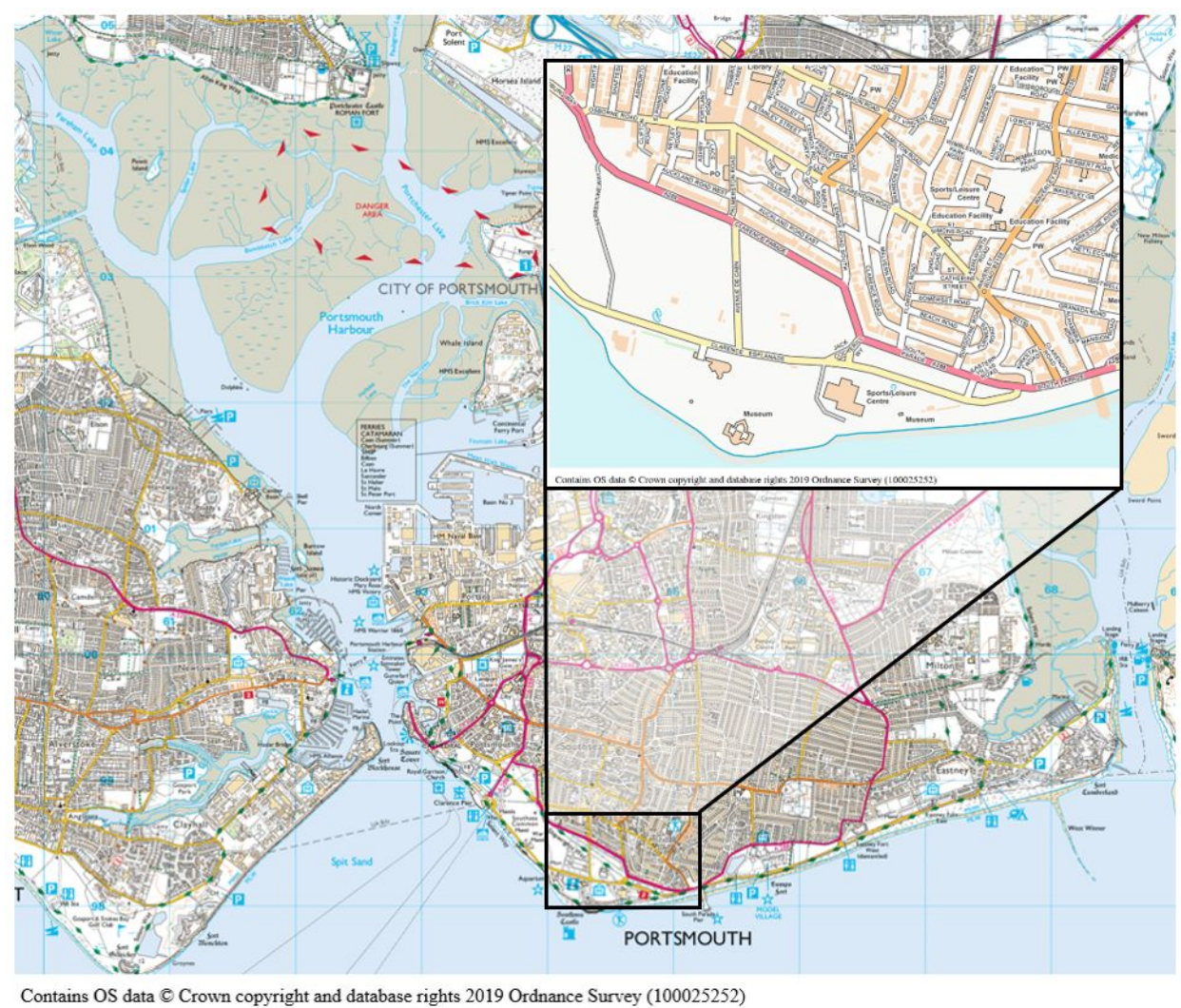

Figure 3. Location of study area - Clearance Parade and South Parade (Ordanance Survey 2019b)

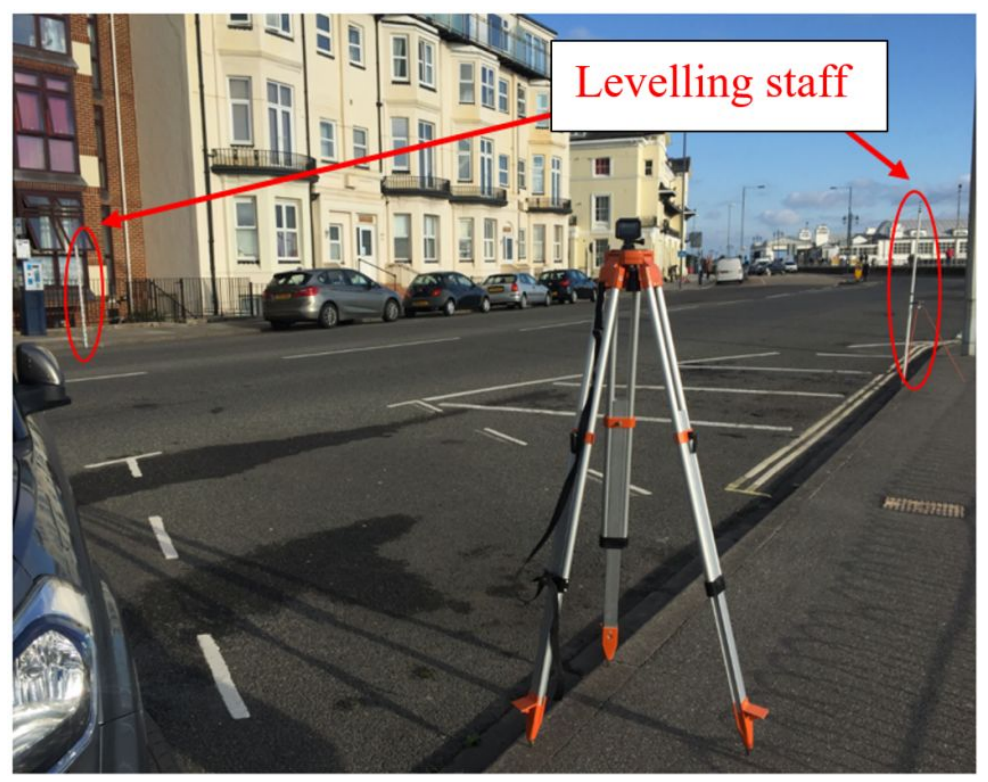

Figure 4. Installation of camcorder 


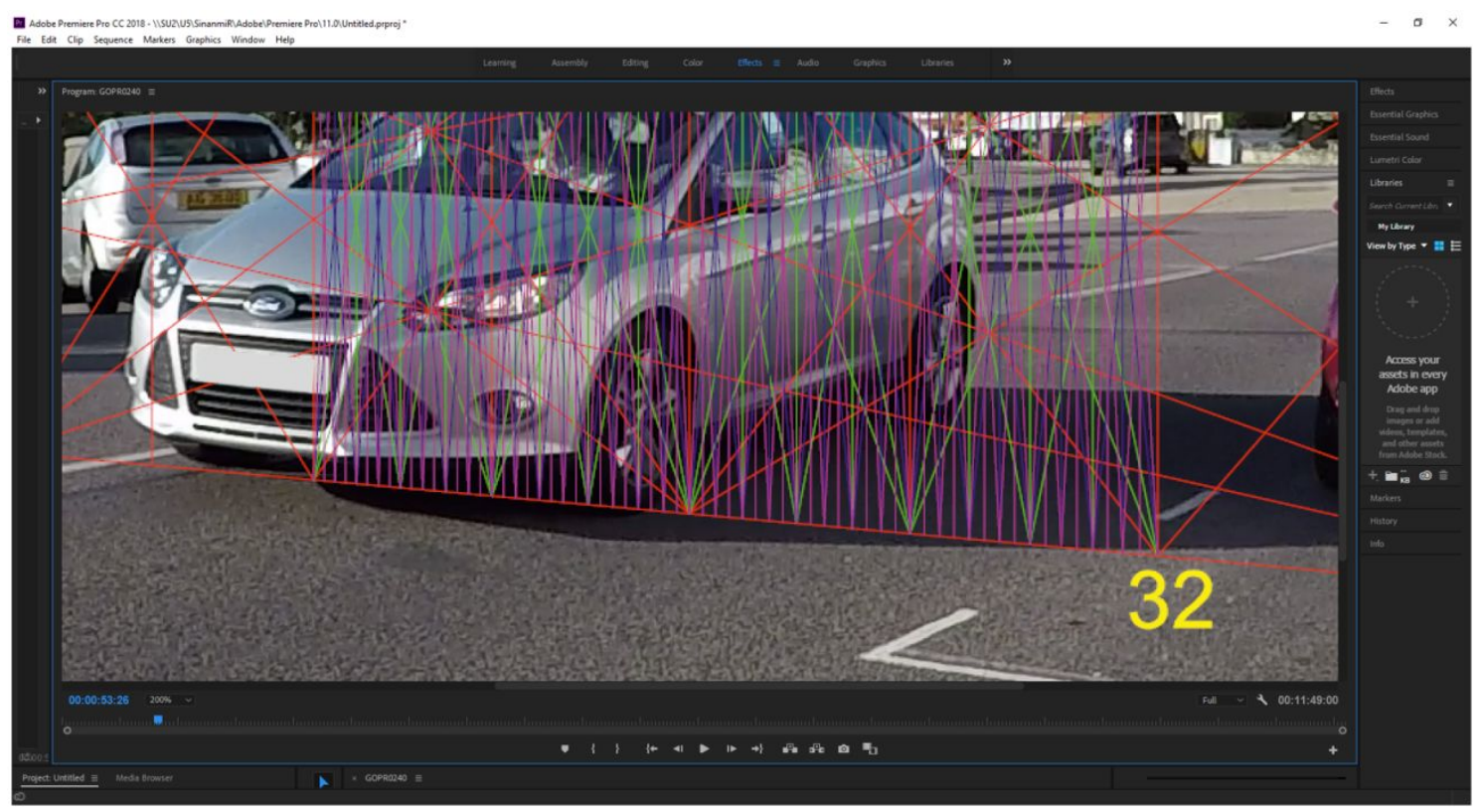

Figure 5. Application of superimposition technique
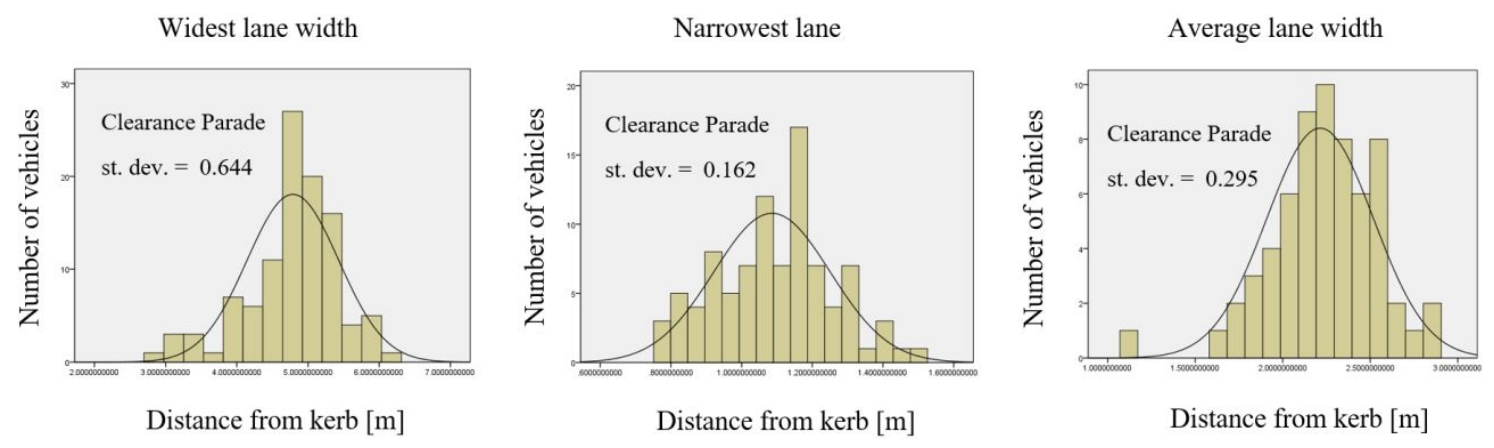

Figure 6. Frequency distribution of vehicles 


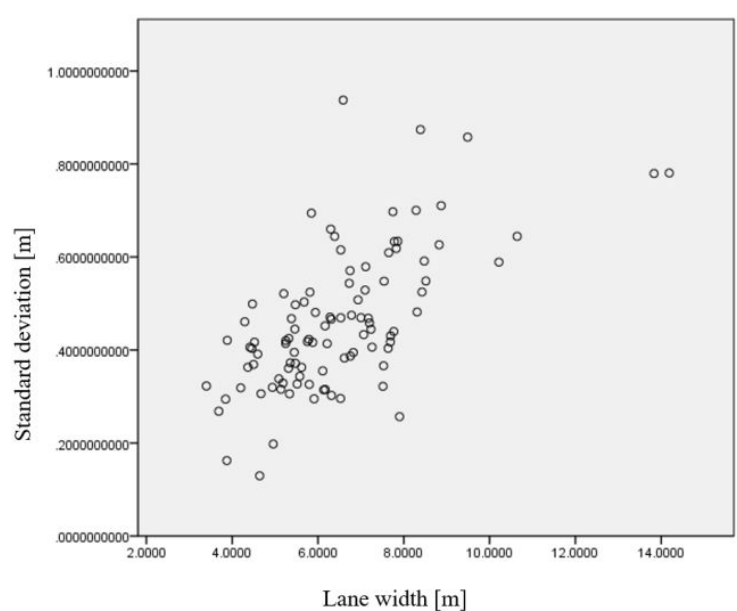

(a)

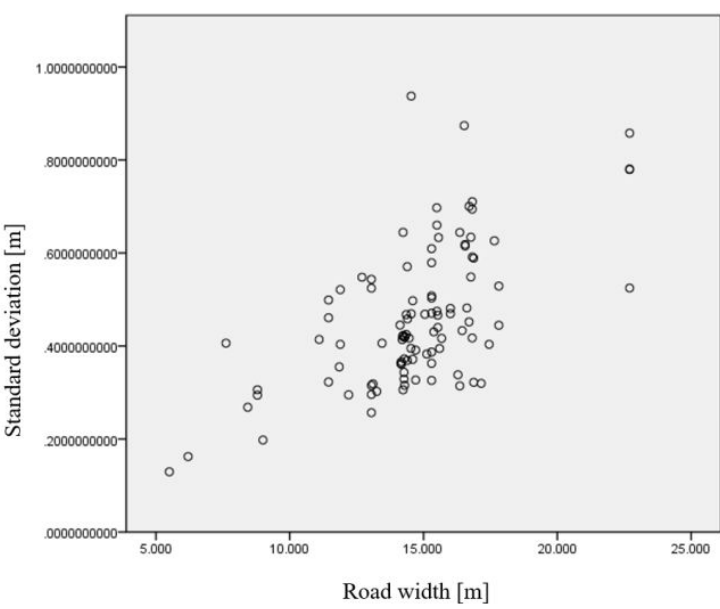

(b)

Figure 7. Scatterplot of the standard deviation with (a) lane width, (b) road width

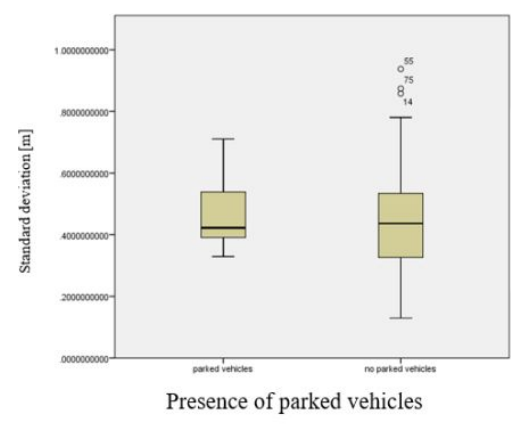

(a)

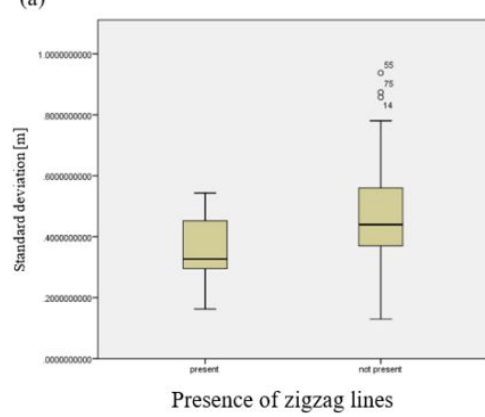

(d)

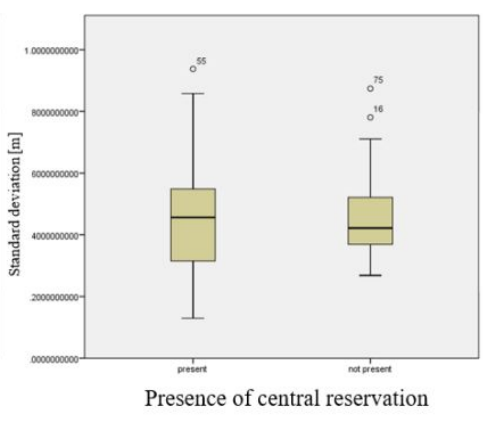

(b)

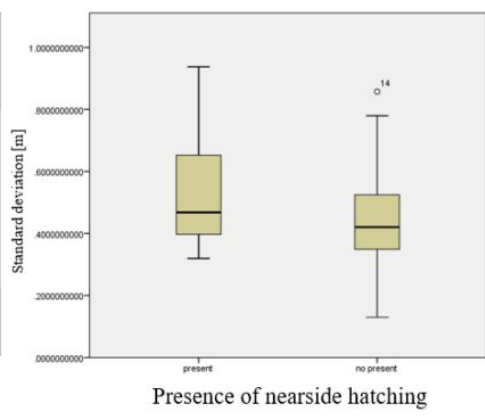

(c)

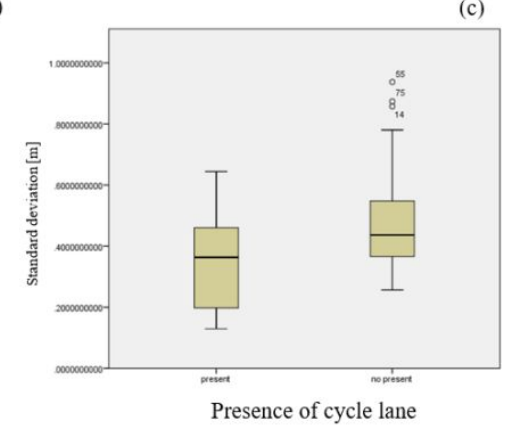

(e)

Figure 8. Boxplot of the channelisation with other road features 


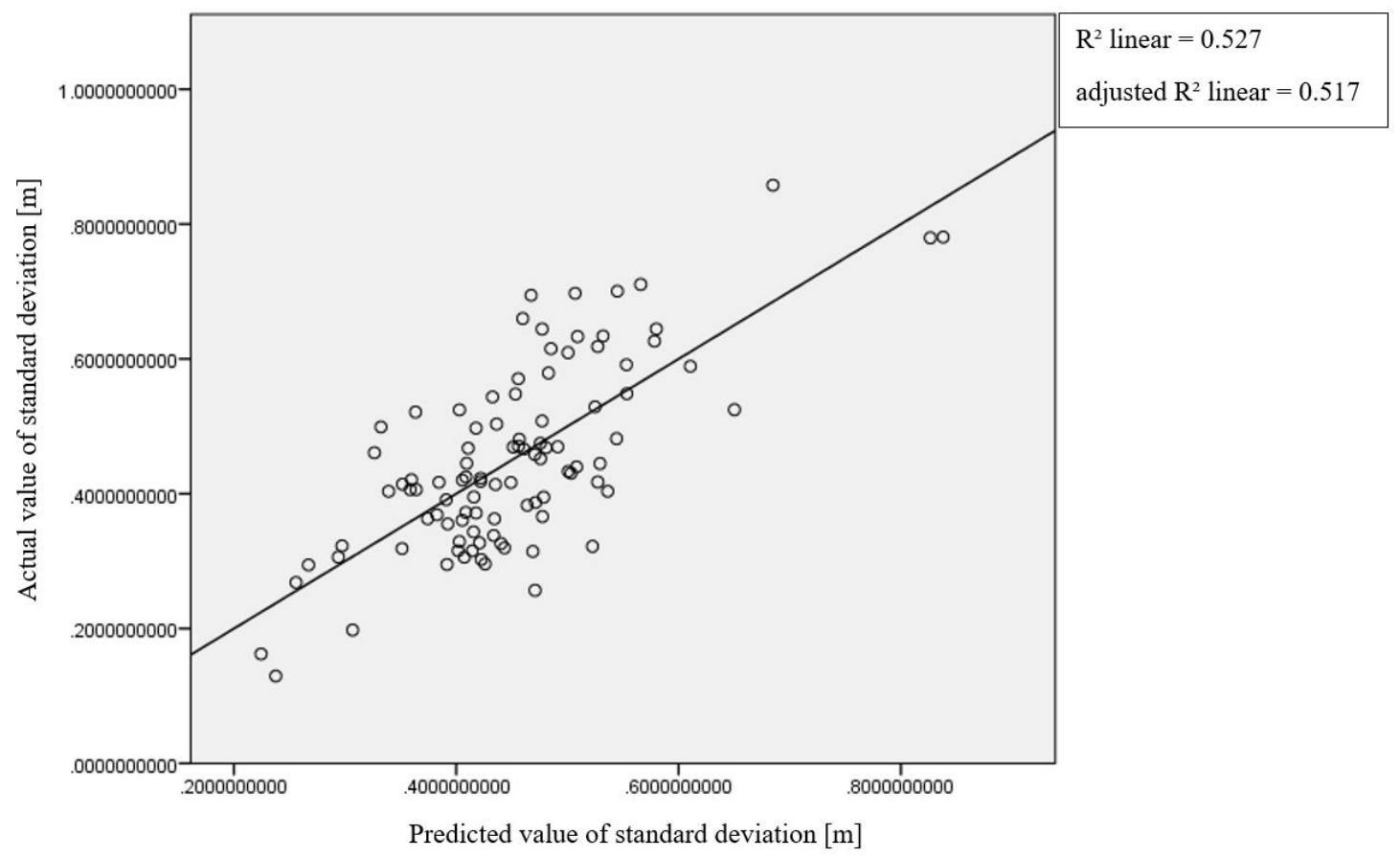

Figure 9. Scatterplot of goodness of model fit

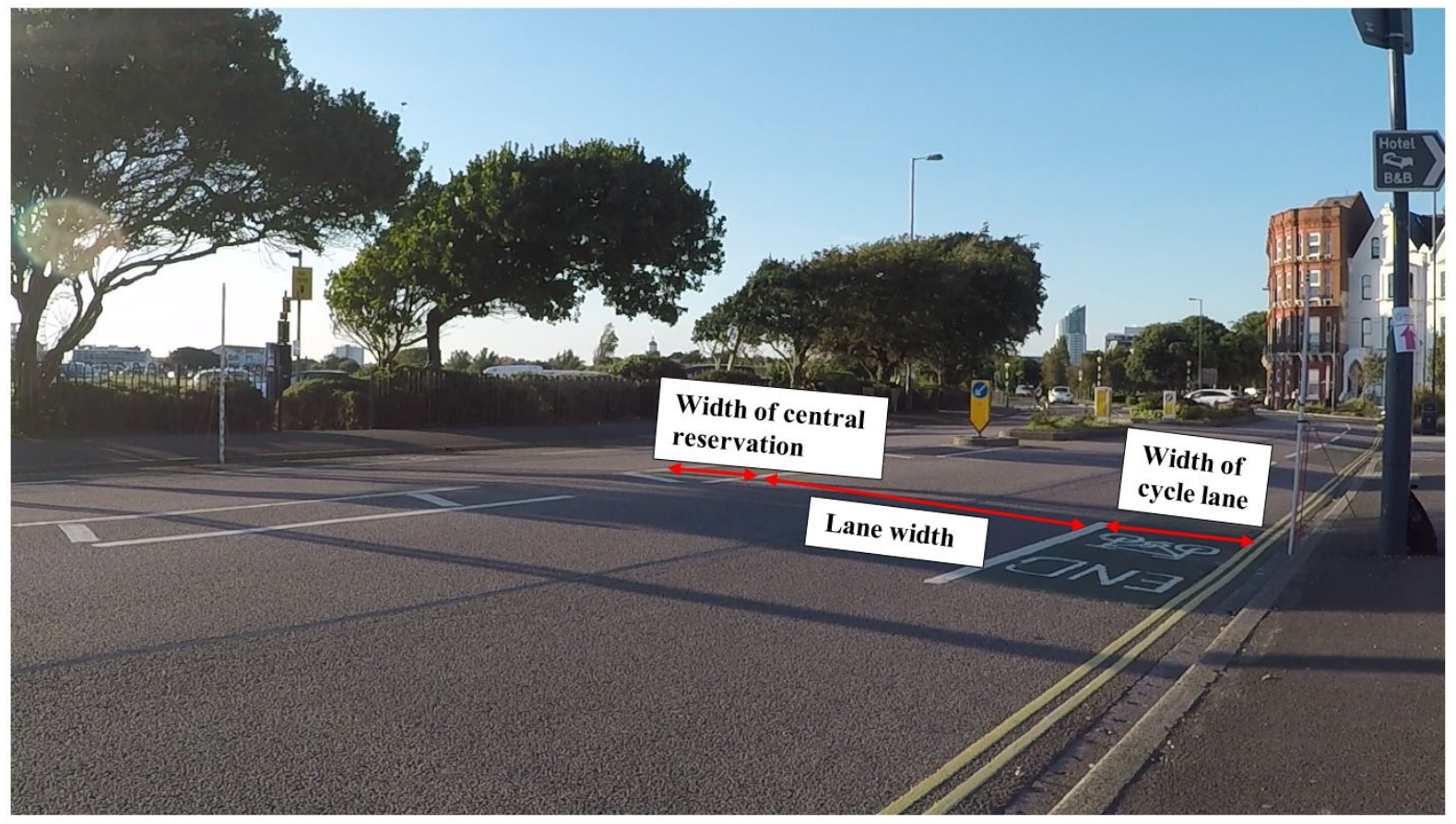

Figure 10. Road section with presence of cycle lane and central reservation 
Table 1. Descriptive statistics of scalable measures obtained in this study

\begin{tabular}{lccc}
\hline Road geometries $(\mathrm{m})$ & & & \\
& Minimum & Maximum & Mean \\
Lane width & 3.40 & 14.19 & 6.46 \\
Road width & 5.50 & 22.70 & 14.70 \\
\hline
\end{tabular}

Table 2. Descriptive statistics of nominal measures obtained in this study

\begin{tabular}{|c|c|}
\hline Presence of road features & $\mathrm{n}$ \\
\hline \multicolumn{2}{|l|}{ Parked vehicles } \\
\hline parked vehicles & 24 \\
\hline no parked vehicles & 76 \\
\hline \multicolumn{2}{|l|}{ Central reservation } \\
\hline present & 34 \\
\hline not present & 66 \\
\hline \multicolumn{2}{|l|}{ Nearside hatching } \\
\hline present & 16 \\
\hline not present & 84 \\
\hline Zigzag lines & 13 \\
\hline present & 13 \\
\hline not present & 87 \\
\hline \multicolumn{2}{|l|}{ Cycle lane } \\
\hline present & 10 \\
\hline not present & 90 \\
\hline
\end{tabular}

Table 3. Results of Multivariate Regression Analysis

\begin{tabular}{rrrrl}
\hline \multirow{2}{*}{ Model } & \multicolumn{3}{c}{ Multivariable analysis } & \\
& Coefficient & \multicolumn{2}{c}{$95 \% \mathrm{CI}$} & $\mathrm{p}$-value \\
& $(\beta)$ & Lower & Upper & \\
\hline Constant & -0.006 & -0.104 & 0.092 & 0.902 \\
Lane width [m] & 0.033 & 0.018 & 0.047 & $1.4 \times 10^{-5}$ \\
Road width [m] & 0.017 & 0.008 & 0.026 & $2.65 \times 10^{-4}$
\end{tabular}

